\title{
The Factor Analysis of the Antecedents of Dry Bulk Terminal for Port Operation Improvement in Malaysia
}

\author{
Norlinda Mohd Rozar ${ }^{\# 1}$, Muhammad Ashlyzan Razik ${ }^{\# 2}$, Mohamad Hazeem Mohmad Sidik ${ }^{\# 3}$ \\ \# Universiti Malaysia Kelantan, Faculty Business and Entrepreneuship, Kampus Kota, \\ Karung Berkunci 36, Pangkalan Chepa, 16100 Kota Bharu, Kelantan, MALAYSIA. \\ ${ }^{1}$ lindarozar78@gmail.com \\ 2ashlyzan@umk.edu.my \\ 33azeemsidik92@gmail.com
}

\begin{abstract}
Seaports are a vital trade gate for almost every nation in the globe. Seaports are now moved from its traditional role for solely providing services for storage or transit to a more important role especially in the wake of rising competition and operating cost. The aim of this study is to analyses the vital components needed for the improvement of the port operation for dry bulk terminals in Malaysia's port. 200 set of questionnaires were distributed involving all of the 18 Federal and States port (Penisular and Borneo) that have dry bulk terminal and only 120 were returned. With a 60 per cent response rate, this is consider as good to justify the result in Malaysia's port. With Cronbach Alpha reliability test of 0.945, the findings found that all of the variables (loading efficiency, infrastructure improvement, time performance and operation improvement) are significant and complementing each other in correlation test. It is recommended for future study to improve the framework by adding more variables or items.
\end{abstract}

Keyword - Dry bulk terminal, operation improvement, Malaysia's port

\section{INTRODUCTION}

In Malaysia, port industry plays a very important role in the growth of its economy and development. It was estimated that $95 \%$ of the Malaysia's international trade is carried out by seaborne (Maritime Institute of Malaysia., 2013). According to the Bernama (2013), Malaysian ports are among the top 20 world busiest port in the world. This reflects that seaport industry has a huge impact on the Malaysia's economy.

Seaports link the sea and the land for transporting goods using different mode of transportations. It connect ships that bring import cargo, or load the export cargo on one side, and onto the road or rail to move the cargo out, or bring in the cargo, as the case may be. According to Maritime Institute of Malaysia (2013) in 2012, Malaysian seaports handled total cargoes of about 480 million of tones from the total 505.26 million tones (RM 127.66 Billion) . It also expected to grow 9.5\% (523.3 million tones = RM 139.74 Billion) in 2013 due to strong sustainable growth in the country and strong intra-Asian trade.

One of the main trades in Malaysia's seaport is Dry Bulk. Dry bulk trades comprises of huge portion of terminal services in the world. Servicing the dry bulk trades are 1,525 terminals located in 1,003 seaports in over 120 countries, of which 317 terminals offer to handle iron ore, 458 bulk fertilizers and 628 coals (Dry Cargo International, 2010).

Hence, to handle such substantial services, efficiency is a priority. For example, reducing the time at the anchorage, berth and also at stockpiles is the main agenda for improving the efficiency of the terminal. The high demand around the world for dry bulk cargo inflicted a lot of pressure on the port terminals to increase their capacity. Many dry bulk terminals around the world are expanding and seriously increasing their capacity due to the high demand for energy and mineral resources (Lodewijks et al., 2009).

In 1993, Malaysia faced with difficulties as the projected cargo was lower than the actual. The lower projected demand delayed new investment to increase the facilities at the port. As a result, the port operation has become slower due to congestion. Therefore, the existing terminals must take on the challenge to improve their efficiency by making an investment, which must take into account on what and how every aspects of dry bulk terminals can be improved. The aim of this paper is to analyses the vital components needed for the improvement of the port operation for dry bulk terminals in Malaysia's port. 


\section{LITERATURE REVIEW}

The basic elements of Port operation in every Port is almost similar. It consists of several similar elements such as ship arrivals at the channel and the berthing operation at the wharves. The operations may include both loading and unloading operations. After this operation, the cargoes are then moves to the transit storage before claimed by the consignee (Park and Kim, 2003). The port's strategic location, accessibility, stateof-the-art facilities and equipment are some of the factors crucial in making the port one of the world's largest and most modern container port. The port's natural harbor conditions and deep waters will be served with links by road, rail and air, which provide easy access. The terminal will also improved the existing infrastructures, operation management, loading efficiency and time performance to sustain their productivity.

Other than that, Bulk cargo is a categorized either as dry Bulk or Break Bulk (Shipping Australia Limited Breakbulk Working Group, 2010). Bulk cargo is also known as general cargo which not using the container for loading onto ships. It is a cargo that is unpacked (un-bundled or un-bound) and homogenous. The bulk cargo is further classified into either dery bulk or liquid bulks. The examples of dry bulk cargoes includes, iron ore, coal,grain, wood chips, cements, dry edibles and bulk mine. For the liquid bulk cargoes the example of it includes oil, LNG, gasoline, chemical and liquid edibles.

\section{Methodology}

The study was conducted using survey questionnaire to identify the requirements needed to improve all of the Malaysia's dry bulk terminal for ports operation. 200 set of questionnaires were distributed involving all of the 18 Federal and States port (Penisular and Borneo) that have dry bulk terminal and only 120 were returned. With a 60 per cent response rate, this is consider as good to justify the result in Malaysia's port. The respondents were chosen using purposive sampling distribution as the respondents were among the general manager, supervisor, manager, assistant manager and executive of the ports. This study is also descriptive and crosssectional. The study data were distributed in july 2013 and respondents were given one month to answer the survey (collected in August 2013).

The questionnaire consists of three parts which are A, B and C. Part A is related to demographic profile such as port name and year of establishment. Meanwhile, part B is asking about the dry bulk element and part $\mathrm{C}$ consists of the requirement needed for the dry bulk terminal with 5 likert scale answer (From $1=$ strongly disagree to $5=$ strongly agree).

\section{Demographics ProfiLe}

It can be inferred in Table 1 that more than 80 per cent of the respondents were from the highest management position. 8 per cent were from general manager, 58 per cent were from manager, followed by 15 per cent of assistant manager. In addition, executive and supervisor took about 19 percent.

TABLE I. Demographic profile

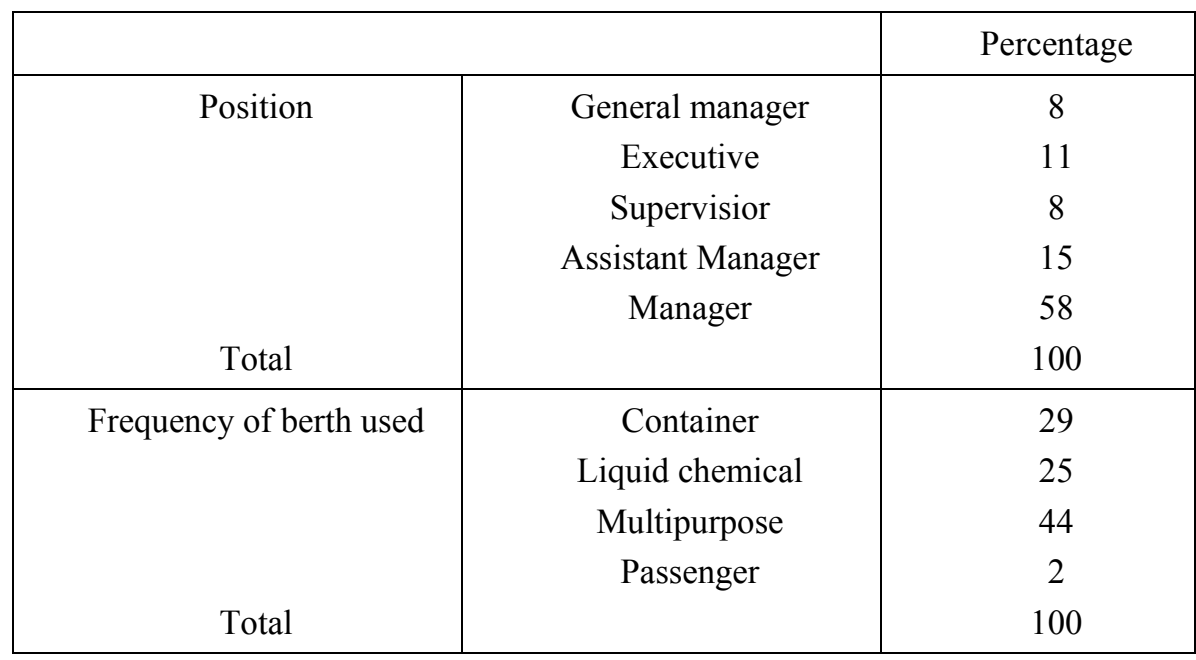




\section{FINDINGS}

The finding found that the questionnaire passed the Cronbach Alpha reliability test with 0.945 . Henceforth, this questionnaire is valid and reliable for further analysis (Hair et al, 2014). The factor analysis of this study was measured using Kaiser-Meyer-Olkin (KMO) test. KMO value more than 0.70 is considered as adequate for each of the items to be considered as reliable to be retained in this study and for further analysis (Cerny and Kaiser, 1977). There are several items that were removed as they fail to pass the KMO test with factor analysis values less than 0.7 . Table 2 depicts the summary of the factor analysis after the removal of several items and variables. To boot, The items and their variables that passed the KMO test were categorized and put into a model as in Figure 1 below. The items were selected from the inclusion in the group of factors. In this analysis, only 17 out of 40 items as in figure 1 below were chosen as othes 23 were considered as inappropriate and should be removed from the questionnaire. Through varimax rotation procedures, schedules and rotated component matrix indicated that the questionnaire items form the four dimensions of the four factors extracted from the questionnaire. Four factors into constructs were loading efficiency, infrastructure improvement, and operation time performance improvement.

TABLE II. Factor Analysis of items studied

\begin{tabular}{|l|l|c|c|c|}
\hline & & \multicolumn{3}{|c|}{ Component } \\
\hline & & 1 & 2 & 3 \\
\hline \multirow{4}{*}{$\begin{array}{l}\text { Loading } \\
\text { Efficiency }\end{array}$} & Loading cost reduction & $\mathbf{0 . 8 2 3}$ & & 0.423 \\
\cline { 2 - 5 } & Trucking efficiency improvement & $\mathbf{0 . 7 6 2}$ & 0.486 & \\
\cline { 2 - 5 } & Loading Work-in-process reduction & $\mathbf{0 . 7 3 9}$ & 0.381 & \\
\cline { 2 - 5 } & Material Handling facility efficiency improvement & $\mathbf{0 . 7 2 9}$ & 0.411 & 0.400 \\
\hline \multirow{4}{*}{$\begin{array}{l}\text { Infrastructure } \\
\text { improvement }\end{array}$} & Stockpile location improvement & & $\mathbf{0 . 7 6 0}$ & 0.450 \\
\cline { 2 - 5 } & Labour improvement & 0.485 & $\mathbf{0 . 7 5 1}$ & \\
\cline { 2 - 5 } & Flexibility (loading) improvement & 0.473 & $\mathbf{0 . 7 2 3}$ & 0.404 \\
\hline \multirow{3}{*}{$\begin{array}{l}\text { Timerformance } \\
\text { perf }\end{array}$} & Loading Processing time reduction & 0.405 & & $\mathbf{0 . 8 1 0}$ \\
\cline { 2 - 5 } & Loading Lead time reduction & & 0.452 & $\mathbf{0 . 7 3 4}$ \\
\cline { 2 - 5 } management & Service quality (loading) improvement & 0.368 & 0.375 & $\mathbf{0 . 7 0 2}$ \\
\cline { 2 - 5 } & Reasonable cost operation & $\mathbf{0 . 9 0 4}$ & & \\
\cline { 2 - 5 } & Port planning capability & $\mathbf{0 . 8 3 3}$ & & \\
\cline { 2 - 5 } & High loading/ unloading flexibility & $\mathbf{0 . 8 2 8}$ & 0.350 & \\
\cline { 2 - 5 } & Smooth gate systems & $\mathbf{0 . 8 2 5}$ & & 0.416 \\
\cline { 2 - 5 } & Transporting service level of connecting road system & $\mathbf{0 . 8 2 0}$ & 0.392 & \\
\cline { 2 - 5 } & Shortest processing time & $\mathbf{0 . 8 0 3}$ & 0.339 & \\
\cline { 2 - 5 } & Control of vehicles, all modes, entering and leaving port & $\mathbf{0 . 7 9 8}$ & & \\
\hline
\end{tabular}




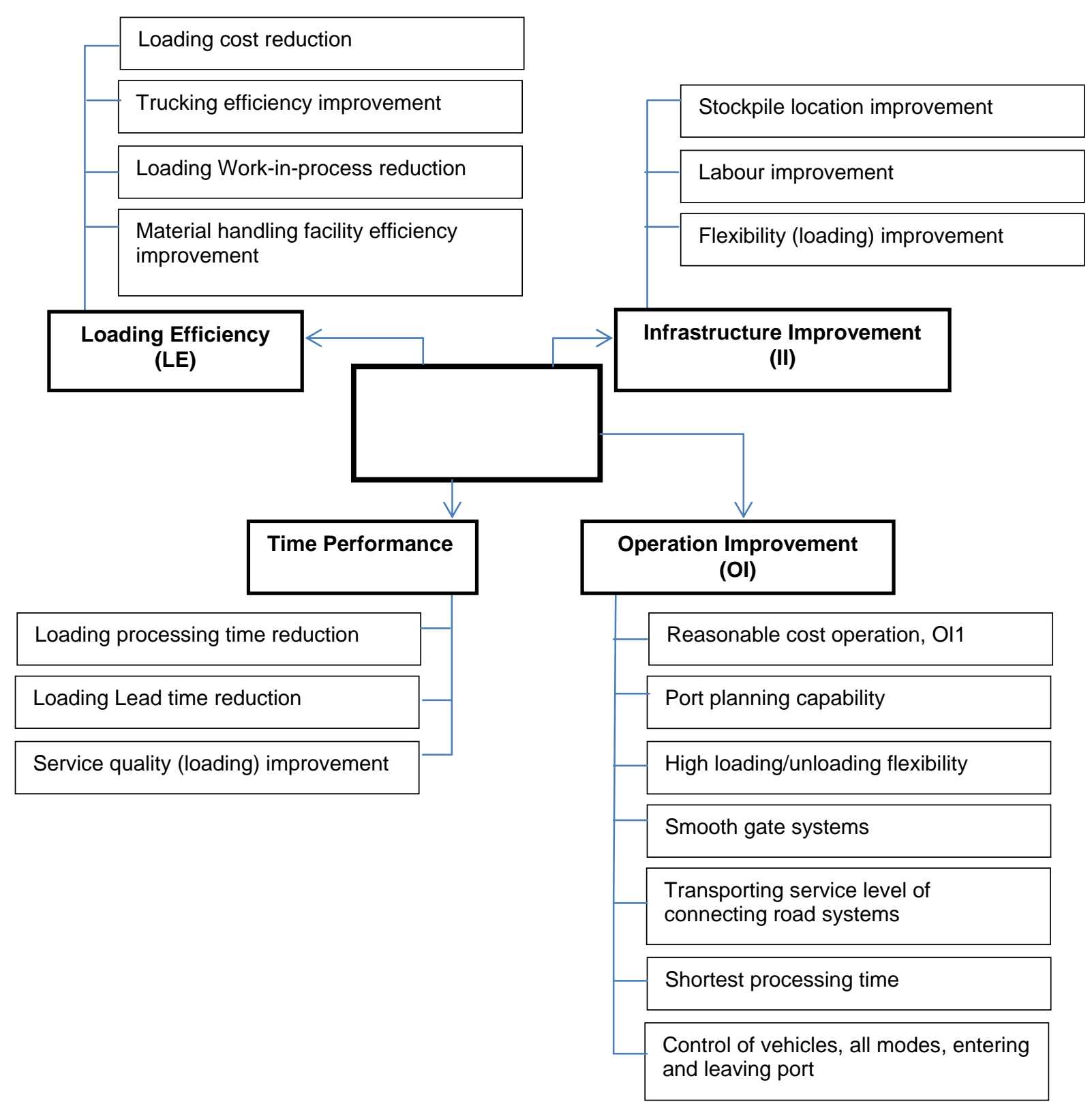

Fig.1 The Most Preferable component for Port Operation

In addition, Table 3 illustrated the spearman correlation between each of the variables understudied for the the most preferable component for port operation. The correlation was done to determine the relationship between each of the variables towards each other. It can be inferred that all of the variables (loading efficiency, infrastructure improvement, time performance and operation improvement) are complimenting with each other. Therefore, all of it needs to be improved and taken care of in Malaysia's port as it will increase the trade efficiency and effectiveness. 
TABLE III. correlation coefficient

\begin{tabular}{ccccc}
\hline Component & $\begin{array}{c}\text { Loading } \\
\text { Efficiency }\end{array}$ & $\begin{array}{c}\text { Infrastructure } \\
\text { Improvement }\end{array}$ & $\begin{array}{c}\text { Time } \\
\text { Performance }\end{array}$ & $\begin{array}{c}\text { Operation } \\
\text { Improvement }\end{array}$ \\
\hline Loading Efficiency & 1 & $* 0.484$ & $* 0.445$ & $* 0.425$ \\
Infrastructure Improvement & & 1 & $* 0.311$ & $* 0.505$ \\
Time Performance & & & 1 & $* 0.738$ \\
Operation Improvement & & & 1 \\
\hline
\end{tabular}

* Significant at $\alpha=0.05, \mathrm{p}$ - value $<0.05$

\section{CONCLUSION}

In summary, the study has provided an empirical approach in determining the critical factors for port improvement in Malaysia. The study also identified four main elements (loading efficiency, infrastructure improvement, time performance and operation improvement) that need to be improved and develop for better port operation in a dry bulk terminal.

\section{LIMITATION AND FUTURE RESEARCH}

Every study comes with limitation and future improvement. This study is conducted only in Dry Bulk terminal in Malaysia port. Hence, it cannot be generalised towards other port that do not consist of Dry Bulk Terminal. Other than that, future study could improve the framework by adding more variables or items.

\section{ACKNOWLEDGMENT}

This research was supported by Research and Innovation of University Malaysia Kelantan. We would like to give thousands of thanks to Mohamad Hazeem Sidik and Norlinda Mohd Rozar at the Faculty of Entrepreneurship and Business of University Malaysia Kelantan for sharing their pearls of wisdom during the course of this research that provided insight and expertise that greatly assisted the research. We thank our colleagues from the Faculty Business and Entrepreneurship of University Malaysia Kelantan for assistance with the particular technique and the methodology and for comments that greatly improved the manuscript

\section{REFERENCES}

[1] Bernama. (2013). Port Klang may have third port in 5-6 years. Retrieved from http://english.astroawani.com/business-news/portklang-may-have-third-port-5-6-years-17466 on 29 November 2018.

[2] Cerny, C.A., and Kaiser, H.F. (1977). A study of a measure of sampling adequacy for factor-analytic correlation matrices. Multivariate Behavioural Research, 12(1), 43-47.

[3] Dry Cargo International. (2010). Dry Cargo Handling Directory, Dry Cargo International Colchester.

[4] Hair, J., Hult, G. T. M., Ringle, C., and Sarstedt, M. (2014). A Primer on Partial Least Squares Structural Equation Modeling (PLSSEM). Los Angeles: SAGE Publications, Incorporated.

[5] Lodewijks, G., Schott, D. L. and Ottjes, J. A. (2009), “Modern Dry Bulk Terminal Design”, Port Technology International, Issue 43, pages $87-94$.

[6] Maritime Institute of Malaysia. (2013). Maritime Institute of Malaysia Research Centre. Retrieved from www.mima.gov.my on 17 Mei 2013

[7] Park, Y.M., and Kim K.H. (2003). A scheduling method for berth and quay cranes. Operational Research Spectrum. 25(1), 1-23.

[8] Shipping Australia Limited Breakbulk Working Group (2010). Break Bulk Shipping Study. New York, Shipping Australia Limited.

\section{AUTHOR PROFILE}

Muhammad Aslyzan bin Razik Currently working as lecturer at Faculty of Entrepreneurship and Business at Universiti Malaysia Kelantan. He is a part time lecturer for Islamic Management at Open University Malaysia and also a Business area at KFORCE, Malaysia. He is examiner for management and business examination for Private Institutes. He is also conducted a research in entrepreneur for Government Institute.

Mohamad Hazeem Mohmad Sidik Currently a PHD student in faculty of Business and Entrepreneurship in Universiti Malaysia Kelantan. An expert in Structural Equation Modeling (SEM). His PHD research is in Logistics and Statistics field.

Norlinda binti Mohd Rozar Currently is a Post Doctoral Researcher, Department of Research and Innovation at University Malaysia Kelantan, Malaysia. Pursuing research in social entrepreneurship area. Received PhD from University Malaysia Pahang in Engineering Technology. Study about the sustainability in business operations, and the particular expertise in statistical and mathematical analysis. 